\title{
Article \\ Clinical Significance and Prognostic Value of Hemostasis Parameters in 337 Patients with Acute Infective Endocarditis
}

\author{
Rosa Zampino ${ }^{1,2}$, Domenico Iossa ${ }^{2,3}$, Maria Paola Ursi ${ }^{1}$, Lorenzo Bertolino ${ }^{1}$, Arta Karruli ${ }^{3}$, Rosa Molaro ${ }^{3}$, \\ Gennaro Esposito 1, Martina Vitrone 1, Fabiana D'Amico 2,3, Rosina Albisinni 2, \\ Emanuele Durante-Mangoni ${ }^{2,3, * \mathbb{D}}$ and on behalf of the Monaldi Hospital CardiovascularInfection Group ${ }^{\dagger}$
}

Citation: Zampino, R.; Iossa, D.; Ursi, M.P.; Bertolino, L.; Karruli, A.; Molaro, R.; Esposito, G.; Vitrone, M.; D'Amico, F.; Albisinni, R.; et al. Clinical Significance and Prognostic Value of Hemostasis Parameters in 337 Patients with Acute Infective Endocarditis. J. Clin. Med. 2021, 10, 5386. https://doi.org/10.3390/ jcm10225386

Academic Editor: Francisco J. Medrano

Received: 6 October 2021

Accepted: 15 November 2021

Published: 18 November 2021

Publisher's Note: MDPI stays neutral with regard to jurisdictional claims in published maps and institutional affiliations.

Copyright: (c) 2021 by the authors. Licensee MDPI, Basel, Switzerland. This article is an open access article distributed under the terms and conditions of the Creative Commons Attribution (CC BY) license (https:/ / creativecommons.org/licenses/by/ $4.0 /)$.
1 Department of Advanced Medical and Surgical Sciences, University of Campania "Luigi Vanvitelli", 80138 Naples, Italy; rosa.zampino@unicampania.it (R.Z.); mariapaola.ursi@hotmail.com (M.P.U.); lorenzo.bertolino91@gmail.com (L.B.); gennaro.esposito6@studenti.unicampania.it (G.E.); martina.vitrone@yahoo.it (M.V.)

2 Unit of Infectious \& Transplant Medicine, A.O.R.N. Ospedali dei Colli-Ospedale Monaldi, 80131 Naples, Italy; Domenico.iossa@unicampania.it (D.I.); fabianadamico@libero.it (F.D.); rosa.albisinni@libero.it (R.A.)

3 Department of Precision Medicine, University of Campania "Luigi Vanvitelli", 80131 Naples, Italy; arta.karruli@unicampania.it (A.K.); rossellamolaro@libero.it (R.M.)

* Correspondence: emanuele.durante@unicampania.it; Tel.: +39-(0)817062475; Fax: +39-(0)817702645

+ Membership of the Monaldi Hospital CardiovascularInfection Group is provided in the Appendix A.

\begin{abstract}
Background: The aim of this study was to assess the clinical significance and prognostic role of the main hemostasis parameters in infective endocarditis (IE): prothrombin time as international normalized ratio (PT-INR), activated partial thromboplastin time (aPTT), fibrinogen, D-dimers, platelet count, homocysteine. (2) Methods: We studied 337 patients with IE. Clinical, hemato-chemical and echocardiography parameters were analyzed. Coagulation parameters were measured on admission. (3) Results: D-dimers levels $(p=0.012)$ and a prolonged PT-INR $(p=0.013)$ were associated with higher in-hospital mortality, while prolonged aPTT ( $p=0.021)$ was associated with increased 1-year mortality. Staphylococcus aureus (S. aureus) infection $(p=0.003)$, prosthetic valve endocarditis (PVE) $(p=0.001)$, surgical indication $(p=0.002)$ and higher D-dimer levels $(p=0.005)$ were independent predictors of in-hospital mortality. PVE $(p=0.001)$, a higher Charlson Comorbidity Index $(p=0.049)$, surgical indication $(p=0.001)$ and prolonged aPTT $(p=0.012)$ were independent predictors of 1-year mortality. Higher levels of D-dimers $(p<0.001)$ and a shorter aPTT $(p<0.001)$ were associated with embolic complications of IE. S. aureus etiology was bound to higher D-dimers levels $(p<0.001)$ and a shorter aPTT $(p=0.006)$. (4) Conclusions: Elevated D-dimers are associated with a higher risk for in-hospital mortality in IE patients. High D-dimers and a short aPTT are associated with a higher risk for embolic events in IE. A longer aPTT is associated with 1-year mortality.
\end{abstract}

Keywords: prognosis; embolism; D-dimers; aPTT; biomarkers

\section{Introduction}

Infective endocarditis (IE) is a potentially fatal disease with a mortality rate of over $20 \%$, largely unmodified over recent decades [1,2]. Mechanisms of IE pathogenesis are still incompletely understood but involve bacteria, host immune responses and the coagulation system [3-6].

Vegetations, the pathologic hallmark of IE, consist of a fibrin mesh wherein platelets and bacteria are embedded. Vegetations form as a consequence of a pathological thromboinflammatory reaction and underlie the progression of the disease and its complications, including heart valve destruction and septic embolic events $[7,8]$. The first step in vegetation formation encompasses an abnormal immune thrombotic reaction with subsequent bacterial entrapment [4,9]. Among major IE causative pathogens, Staphylococcus aureus directly promotes coagulation, generating thrombin-like activity by staphylocoagulase 
and von Willebrand factor (vWF)-binding protein, making up staphylothrombin [10]. Staphylothrombin mediates the conversion of fibrinogen to fibrin and initiates platelet (PLT) aggregation [11]. Intriguingly, the inhibition of staphylothrombin by dabigatran was safe and effective in reducing coagulation activation, time to blood culture clearance and metastatic foci of infection in S. aureus bacteremia, including IE [12].

These data strongly suggest it could be beneficial to monitor and modulate coagulation in IE. Among coagulation parameters, D-dimers have been previously identified as a marker able to provide important insights into the infection-related coagulation abnormalities [13-15]. Three studies have evaluated the prognostic role of D-dimers in IE. Turak and colleagues suggested that high D-dimers levels on admission could identify IE patients at increased risk for in-hospital mortality [16]. Lin et al. found D-dimers as a prognostic factor of in-hospital adverse events and six-month mortality [17], while Xu et al. found that higher plasma D-dimers levels were predictive of ischemic stroke in 173 patients with IE [18]. However, use of coagulation markers in the prediction of IE prognosis has not yet entered into clinical practice [19].

Therefore, the primary aim of this study was to assess whether routine hemostasis parameters (PLT count, prothrombin time as international normalized ratio (PT-INR), activated partial thromboplastin time (aPTT), fibrinogen and D-dimers) have prognostic value for in-hospital and 1-year mortality in patients with IE. The secondary objective was to analyze the possible association of hemostasis markers with IE clinical features, microbial etiology, comorbidities and complications.

\section{Materials and Methods}

\subsection{Study Design}

In this retrospective study, we included patients with a diagnosis of definite IE, admitted between 2007 and 2019 at the Unit of Infectious and Transplant Medicine, Monaldi Hospital, University of Campania "Luigi Vanvitelli". IE diagnosis was made according to the current criteria (modified Duke criteria until 2014, and ESC criteria from 2015 on) [19,20]. In the study period, we observed 525 IE cases in our hospital, a regional referral center for IE. Out of these, we included in this study all patients $(n=337)$ admitted to our unit with a recent diagnosis of IE (definite or possible) without the need for emergency surgery. Complete data were not available for all enrolled patients, as some coagulation parameters were not recorded in our database in the first years of the accrual time; the number of patients for whom each parameter was available is specified in Table 1.

Table 1. Baseline characteristics of the study group.

\begin{tabular}{ccc}
\hline Parameter & Missing Data & Result \\
\hline Patient number & - & 337 \\
\hline Age, years & - & $64(51-73)$ \\
\hline Male gender & - & $237(70.3)$ \\
\hline Chronic heart failure (prior to IE onset) & - & $100(29.7)$ \\
\hline Charlson Comorbidity Index & 139 & $5(3-7)$ \\
\hline Diabetes mellitus & - & $62(18.4)$ \\
\hline Chronic hepatitis & - & $61(18.1)$ \\
\hline Chronic kidney disease $(S t a g e s ~ 3-5)$ & - & $59(17.5)$ \\
\hline Platelet count, cells $10^{3} / \mu \mathrm{L}$ & - & $203(149-262)$ \\
\hline Creatinine, $\mathrm{mg} / \mathrm{dL}$ & - & $1.0(0.8-1.3)$ \\
\hline Troponin I, ng/mL & 59 & $0.05(0.02-0.53)$ \\
\hline D-dimers, ng $/ \mathrm{mL}$ & 32 & $605(296-1101)$ \\
\hline PT-INR & - & $1.3(1.18-1.3)$ \\
\hline
\end{tabular}


Table 1. Cont.

\begin{tabular}{|c|c|c|}
\hline Parameter & Missing Data & Result \\
\hline Fibrinogen, $\mathrm{mg} / \mathrm{dL}$ & 134 & $407(322-532)$ \\
\hline aPTT, seconds & 5 & $32.5(29.7-38.1)$ \\
\hline Homocysteine, $\mathrm{mcmol} / \mathrm{L}$ & 82 & $15(12-20)$ \\
\hline C-reactive protein, $\mathrm{mg} / \mathrm{dL}$ & 2 & $5.2(2.4-9.9)$ \\
\hline $\begin{array}{c}\text { Vegetation location } \\
-\quad \text { Aortic valve } \\
-\quad \text { Mitral valve } \\
-\quad \text { Tricuspid/pulmonary valve } \\
\text { - Cardiac implantable electronic device } \\
-\quad \text { Multivalve involvement } \\
-\quad \text { Other }\end{array}$ & 2 & $\begin{array}{l}115(34.3) \\
79(23.6) \\
25(7.5) \\
86(25.7) \\
28(8.4) \\
2(0.6)\end{array}$ \\
\hline $\begin{array}{c}\text { IE type: } \\
-\quad \text { Native valve } \\
-\quad \text { Prosthetic valve } \\
-\quad \text { Cardiac implantable electronic device } \\
-\quad \text { Other }\end{array}$ & 2 & $\begin{array}{c}145(43.3) \\
93(27.8) \\
86(25.7) \\
11(3.3)\end{array}$ \\
\hline $\begin{array}{c}\text { IE causative pathogen: } \\
-\quad \text { Streptococci } \\
\text { - Coagulase-negative Staphylococci } \\
-\quad \text { Staphylococcus aureus } \\
-\quad \text { Enterococci } \\
\text { - Negative cultures } \\
-\quad \text { Gram negatives } \\
-\quad \text { Other pathogens }\end{array}$ & - & $\begin{array}{l}97(28.8) \\
63(18.7) \\
53(15.7) \\
52(15.4) \\
49(14.5) \\
14(4.2) \\
9(2.7)\end{array}$ \\
\hline Vegetation size (max. dimension), mm (n. 257) & 80 & $14(9-20)$ \\
\hline Embolic event & - & $104(30.9)$ \\
\hline Cardiac surgery & - & $208(62.3)$ \\
\hline In-hospital mortality & - & $32(9.5)$ \\
\hline 1-year mortality & 70 & $76(22.6)$ \\
\hline
\end{tabular}

Data are expressed as median and interquartile range (IQR) or number and percentages (\%). Abbreviations: IE: infective endocarditis; PT-INR: prothrombin time international normalized ratio; aPTT: activated partial thromboplastin time.; $\mathrm{n}$.: number of patients with available data.

This study was approved by the Ethics Committee of the University of Campania "Luigi Vanvitelli" and AORN Ospedali dei Colli (prot. N. AOC/011110/2020). Informed consent was obtained from patients for the anonymous collection and use of their clinical data.

\subsection{Patients}

Data of patients were available as part of a standardized protocol of IE evaluation followed at our unit, which includes a baseline clinical assessment, particularly of clinical history, physical examination, chest X-ray, abdominal ultrasound scan and hemato-chemical tests (including full blood count, PT-INR, aPTT, fibrinogen, D-dimers, C-reactive protein (CRP), creatinine, urea, glycemia, alanine transferase (ALT)). According to the protocol, a trans-thoracic echocardiogram (TTE) was performed in all patients within $72 \mathrm{~h}$ of admission, followed by a transesophageal echocardiogram (TEE) where needed. Detailed information about IE characteristics (native or prosthetic valve, or cardiac implantable electronic device (CIED)), endocardial vegetations (number, size and position) and isolated causative pathogens was also collected. Embolic events, defined as acute complications causing overt clinical manifestations [21], and their characteristics (location, extension, complications) were also recorded. 
The Charlson Comorbidity Index (CCI) was calculated for each patient, and the estimated glomerular filtration rate (eGFR) was computed by the Modification of Diet in Renal Disease (MDRD) formula. Anticoagulant treatment is also reported.

\subsection{Laboratory Assays}

Hemato-chemical parameters were obtained by routine methods used in our hospital's central laboratory and included main hemostasis parameters (prothrombin time as international normalized ratio (PT-INR), activated partial thromboplastin time (aPTT), fibrinogen, D-dimers, platelet count, homocysteine), and biochemical markers, such as CRP and troponin. Hemato-chemical parameters used for this study were collected on hospital admission.

\subsection{Statistical Analysis}

Numerical data are presented as the median with the interquartile range, and categorical/nominal data as the number and percentage. The Mann-Whitney $U$ test and the Kruskal-Wallis test were used to assess the statistical significance of differences between two or more subgroups of numerical variables. Fisher's exact test was used to compare subgroups for nominal variables. Logistic regression analysis of independent predictors of hospital and 1-year mortality was performed by block entering in the model all variables significantly associated with each of these outcomes in univariate analysis. To assess the predictive performance of hemostasis parameters on IE outcome, we calculated the area under the receiver operating characteristic (ROC) curve, entering in-hospital mortality as the state variable.

The significance level was set at 5\%, and all tests were 2-tailed. All analyses were performed using the statistical software for Windows SPSS 20 (SPSS, Inc., Chicago, IL, USA).

\section{Results}

\subsection{Clinical Features and Coagulation Parameters of the Study Population}

Clinical features and coagulation parameters of the 337 IE patients studied are shown in Table 1. The median age was 64 years, and $70.3 \%(n=237)$ were males. The most frequent causative pathogens of IE were staphylococci and streptococci. The aortic valve and native heart valves were the most frequent sites affected by the infection. In this cohort, the in-hospital mortality rate was $9.5 \%, 1$-year mortality was $22.7 \%$ and 70 patients $(21 \%)$ were lost to long-term follow-up.

Data on anticoagulant treatment on admission were available for 307 patients, of whom 80 were treated with warfarin, 17 were heparin-treated patients and 210 were not on anticoagulant treatment $(p=0.103)$.

\subsection{Hemostasis Parameters and IE Mortality}

Coagulation parameters were evaluated in relation to in-hospital and 1-year mortality of IE patients (Table 2). In-hospital mortality was associated with higher D-dimers levels $(p=0.012)$ and prolonged PT-INR $(p=0.013)$, while 1 -year mortality was associated with prolonged aPTT $(p=0.021)$. 
Table 2. Coagulation parameters in relation to major clinical features and mortality of IE patients.

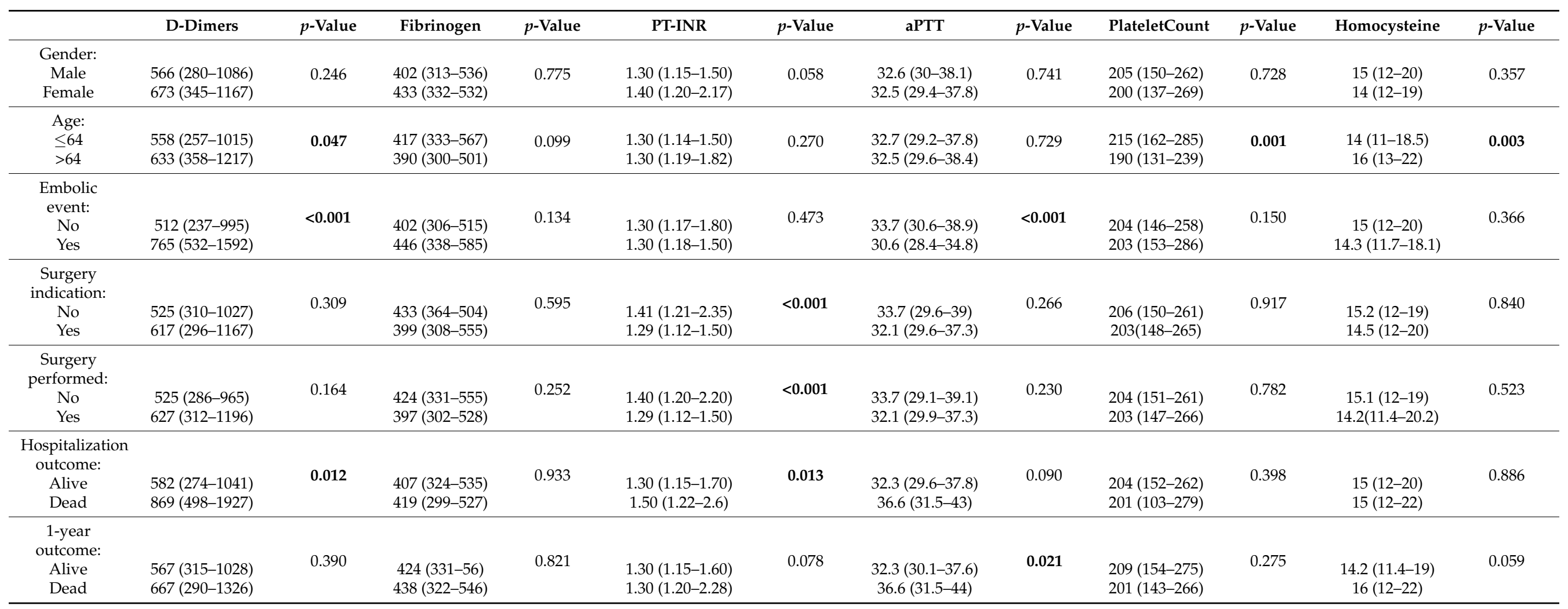

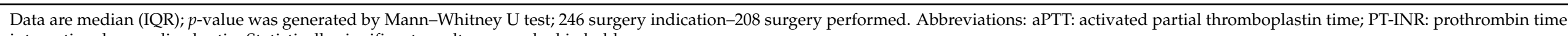
international normalized ratio. Statistically significant results are marked in bold. 
In multivariate logistic regression analysis, S. aureus infection $(p=0.003)$, prosthetic valve endocarditis (PVE) $(p=0.001)$, indication for surgery $(p=0.002)$ and higher D-dimers levels $(p=0.005)$ were independently associated with in-hospital mortality (Table 3A). Moreover, PVE $(p=0.001)$, higher CCI $(p=0.049)$, surgical indication $(p=0.001)$ and prolonged aPTT $(p=0.012)$ were independent predictors of 1-year mortality (Table 3B).

Table 3. Parameters associated with in-hospital mortality (panel A) and 1-year mortality (panel B).

\begin{tabular}{|c|c|c|c|c|c|c|}
\hline \multirow{3}{*}{ Parameter } & \multicolumn{4}{|c|}{ A } & & \\
\hline & \multicolumn{2}{|c|}{ In-Hospital Mortality } & \multicolumn{2}{|c|}{ Univariate Analysis } & \multicolumn{2}{|c|}{$\begin{array}{c}\text { Multivariate Logistic } \\
\text { Regression Analysis }\end{array}$} \\
\hline & $\begin{array}{c}\text { Survived } \\
(n=305)\end{array}$ & $\begin{array}{l}\text { Deceased } \\
(n=32)\end{array}$ & $\begin{array}{c}\text { Odds Ratio } \\
\text { (95\% C.I.) }\end{array}$ & $p$-Value & $\begin{array}{c}\text { Odds Ratio } \\
\text { (95\% C.I.) }\end{array}$ & $p$-Value \\
\hline Age & $64(50-73)$ & $68(55-75)$ & & 0.113 & & \\
\hline \multicolumn{7}{|l|}{ Gender: } \\
\hline Male & $213(69.84)$ & $24(75)$ & 0.77 & \multirow{2}{*}{0.685} & & \\
\hline Female & $92(30.16)$ & $8(25)$ & $(0.33-1.78)$ & & & \\
\hline \multicolumn{7}{|l|}{ IE etiology: } \\
\hline S. aureus & $47(15.4)$ & $6(18.75)$ & & \multirow{7}{*}{0.004} & \multirow{7}{*}{$\begin{array}{c}1.57 \\
(1.16-2.13)\end{array}$} & \multirow{7}{*}{0.003} \\
\hline Coagulase-negative Staphylococci & 55 (18.03) & $8(25)$ & & & & \\
\hline Streptococci & $95(31.1)$ & $2(6.25)$ & & & & \\
\hline Enterococci & $48(15.7)$ & $4(12.5)$ & & & & \\
\hline Gram negatives & $10(3.2)$ & $4(12.5)$ & & & & \\
\hline Other pathogens & $6(1.9)$ & $3(9.3)$ & & & & \\
\hline Negative cultures & $44(14.4)$ & $5(15.7)$ & & & & \\
\hline Infection type: & $(\mathrm{n}=218)$ & $(\mathrm{n}=20)$ & \multirow{3}{*}{$\begin{array}{c}4.10 \\
(1.51-11.10)\end{array}$} & \multirow{3}{*}{0.004} & \multirow{3}{*}{$\begin{array}{c}10.49 \\
(2.79-39.48)\end{array}$} & \multirow{3}{*}{0.001} \\
\hline Native & $139(63.7)$ & $6(30)$ & & & & \\
\hline Prosthetic & $79(36.3)$ & $14(70)$ & & & & \\
\hline \multirow{2}{*}{ Charlson Comorbidity Index } & $(\mathrm{n}=180)$ & $(\mathrm{n}=18)$ & \multirow{2}{*}{\multicolumn{2}{|c|}{0.253}} & & \\
\hline & $5(3-7)$ & $6(4-7)$ & & & & \\
\hline Embolic event *: & & & \multirow{3}{*}{$\begin{array}{c}1.19 \\
(0.55-2.57)\end{array}$} & \multirow{3}{*}{0.689} & & \\
\hline Yes & $93(30.5)$ & $11(34.4)$ & & & & \\
\hline No & $212(69.5)$ & $21(65.6)$ & & & & \\
\hline Intracardiac abscess & & & \multirow{3}{*}{$\begin{array}{c}2.34 \\
(0.98-5.58)\end{array}$} & \multirow{3}{*}{0.059} & & \\
\hline Yes & $38(12.4)$ & $8(25)$ & & & & \\
\hline No & $267(87.6)$ & $24(75)$ & & & & \\
\hline Surgery indication: & $(n=303)$ & $(n=32)$ & \multirow{3}{*}{$\begin{array}{c}3.83 \\
(1.13-12.90)\end{array}$} & \multirow{3}{*}{0.020} & \multirow{3}{*}{$\begin{array}{c}14.07 \\
(2.68-73.80)\end{array}$} & \multirow{3}{*}{0.002} \\
\hline Yes & $217(71.6)$ & $29(90.6)$ & & & & \\
\hline No & $86(28.4)$ & $3(9.4)$ & & & & \\
\hline D-dimers, ng/mL & $\begin{array}{c}582 \\
(274-1041)\end{array}$ & $\begin{array}{c}869 \\
(498-1927)\end{array}$ & & 0.012 & $\begin{array}{c}1.00 \\
(1.00-1.00)\end{array}$ & 0.005 \\
\hline Fibrinogen, mg/dL & $407(324-535)$ & 419 (299-527) & \multicolumn{2}{|r|}{0.933} & & \\
\hline PT-INR & $\begin{array}{c}1.30 \\
(1.15-1.70)\end{array}$ & $1.50(1.22-2.6)$ & & 0.013 & $\begin{array}{c}1.61 \\
(0.94-2.74)\end{array}$ & 0.077 \\
\hline aPTT, seconds & $\begin{array}{c}32.3 \\
(29.6-37.8)\end{array}$ & $36.6(31.5-43)$ & & 0.090 & & \\
\hline Platelet count, cells $10^{3} / \mu \mathrm{L}$ & $204(152-262)$ & $201(103-279)$ & & 0.398 & & \\
\hline Homocysteine, $\mathrm{mcmol} / \mathrm{L}$ & $15(12-20)$ & $15(12-22)$ & & 0.886 & & \\
\hline
\end{tabular}


Table 3. Cont.

\begin{tabular}{|c|c|c|c|c|c|c|}
\hline \multirow{3}{*}{ Parameter } & \multicolumn{4}{|c|}{ B } & & \\
\hline & \multicolumn{2}{|c|}{ 1-Year Mortality } & \multicolumn{2}{|c|}{ Univariate Analysis } & \multicolumn{2}{|c|}{$\begin{array}{c}\text { Multivariate Logistic } \\
\text { Regression Analysis }\end{array}$} \\
\hline & $\begin{array}{c}\text { Survived } \\
(n=191)\end{array}$ & $\begin{array}{c}\text { Deceased } \\
(n=76)\end{array}$ & $\begin{array}{c}\text { Odds Ratio } \\
\text { (95\% C.I.) }\end{array}$ & $p$-Value ^ & $\begin{array}{l}\text { Odds Ratio } \\
\text { (95\% C.I.) }\end{array}$ & $p$-Value \\
\hline Age & $62(49-73)$ & $65(55-75)$ & & 0.058 & & \\
\hline $\begin{array}{l}\text { Gender: } \\
\text { Male } \\
\text { Female }\end{array}$ & $\begin{array}{c}130(68.1) \\
61(31.9)\end{array}$ & $\begin{array}{l}55(72.3) \\
21(27.7)\end{array}$ & $\begin{array}{c}0.81 \\
(0.45-1.46)\end{array}$ & 0.558 & & \\
\hline $\begin{array}{c}\text { IE etiology: } \\
\text { S. aureus } \\
\text { Coagulase-negative Staphylococci } \\
\text { Streptococci } \\
\text { Enterococci } \\
\text { Gram negatives } \\
\text { Other pathogens } \\
\text { Negative cultures }\end{array}$ & $\begin{array}{c}25(13.1) \\
34(17.8) \\
69(36.1) \\
34(17.8) \\
6(3.1) \\
3(1.6) \\
20(10.5)\end{array}$ & $\begin{aligned} & 12(15.8) \\
& 18(23.7) \\
& 12(15.8) \\
& 11(14.5) \\
& 5(6.6) \\
& 3(3.9) \\
& 15(19.7)\end{aligned}$ & & 0.017 & $\begin{array}{c}1.34 \\
(0.92-1.96)\end{array}$ & 0.123 \\
\hline $\begin{array}{c}\text { Infection type: } \\
\text { Native } \\
\text { Prosthetic }\end{array}$ & $\begin{array}{l}(\mathrm{n}=141) \\
93(66) \\
48(34)\end{array}$ & $\begin{array}{l}(\mathrm{n}=51) \\
24(47) \\
27(53)\end{array}$ & $\begin{array}{c}2.18 \\
(1.13-4.17)\end{array}$ & 0.020 & $\begin{array}{c}12.90 \\
(3.02-55.09)\end{array}$ & 0.001 \\
\hline Charlson Comorbidity Index & $\begin{array}{c}(\mathrm{n}=110) \\
5(2-7)\end{array}$ & $\begin{array}{l}(\mathrm{n}=36) \\
6(4.2-7)\end{array}$ & & 0.009 & $\begin{array}{c}1.32 \\
(1.00-1.74)\end{array}$ & 0.049 \\
\hline $\begin{array}{c}\text { Embolic event *: } \\
\text { Yes } \\
\text { No }\end{array}$ & $\begin{array}{c}61(32) \\
130(68)\end{array}$ & $\begin{array}{l}20(26.3) \\
56(73.7)\end{array}$ & $\begin{array}{c}0.76 \\
(0.42-1.37)\end{array}$ & 0.461 & & \\
\hline $\begin{array}{c}\text { Intracardiac abscess } \\
\text { Yes } \\
\text { No }\end{array}$ & $\begin{array}{c}25(15.5) \\
136(84.5)\end{array}$ & $\begin{array}{l}13(17.1) \\
63(82.9)\end{array}$ & $\begin{array}{c}1.37 \\
(0.66-1.84)\end{array}$ & 0.439 & & \\
\hline $\begin{array}{c}\text { Surgery indication: } \\
\text { Yes } \\
\text { No }\end{array}$ & $\begin{array}{c}133(70) \\
57(30)\end{array}$ & $\begin{array}{l}66(86.8) \\
10(13.2)\end{array}$ & $\begin{array}{c}3.83 \\
(1.13-12.90)\end{array}$ & 0.005 & $\begin{array}{c}2.59 \\
(4.515-235.17)\end{array}$ & 0.001 \\
\hline D-dimers, ng/mL & $\begin{array}{c}567 \\
(315-1028)\end{array}$ & $\begin{array}{c}667 \\
(290-1326)\end{array}$ & & 0.390 & & \\
\hline Fibrinogen, $\mathrm{mg} / \mathrm{dL}$ & $424(331-567)$ & $438(322-546)$ & & 0.821 & & \\
\hline PT-INR & $\begin{array}{c}1.30 \\
(1.15-1.60) \\
\end{array}$ & $\begin{array}{c}1.30 \\
(1.20-2.28) \\
\end{array}$ & & 0.078 & & \\
\hline aPTT, seconds & $\begin{array}{c}32.3 \\
(30.1-37.6)\end{array}$ & $36.6(31.5-44)$ & & 0.021 & $\begin{array}{c}1.09 \\
(1.02-1.17)\end{array}$ & 0.012 \\
\hline Platelet count, cells $10^{3} / \mu \mathrm{L}$ & $209(154-275)$ & $201(143-266)$ & & 0.275 & & \\
\hline Homocysteine, $\mu \mathrm{mol} / \mathrm{L}$ & $14.2(11.4-19)$ & $16(12-22)$ & & 0.059 & & \\
\hline
\end{tabular}

Data are presented as median with interquartile range (IQR) or as number and percentage (\%). ^ The $p$-value was generated by Fisher's exact test or Pearson chi-square test for categorical variables, and Mann-Whitney for numerical variables; ${ }^{*}$ includes stroke. Abbreviations: aPTT: activated partial thromboplastin time; IE: infective endocarditis; PT-INR: prothrombin time international normalized ratio. Statistically significant values are marked in bold.

Regarding anticoagulation treatment, no significant differences were observed regarding in-hospital mortality between patients treated with anticoagulants (14/97) and those not treated with anticoagulants $(17 / 210 ; p=0.103)$. There was also no significant difference in 1-year mortality between anticoagulant-treated (26/97) and untreated (43/210; $p=0.24)$ patients.

The predictive performance of hemostasis parameters for in-hospital mortality as assessed by the area under the ROC curves appeared to be fair (Figure 1). 


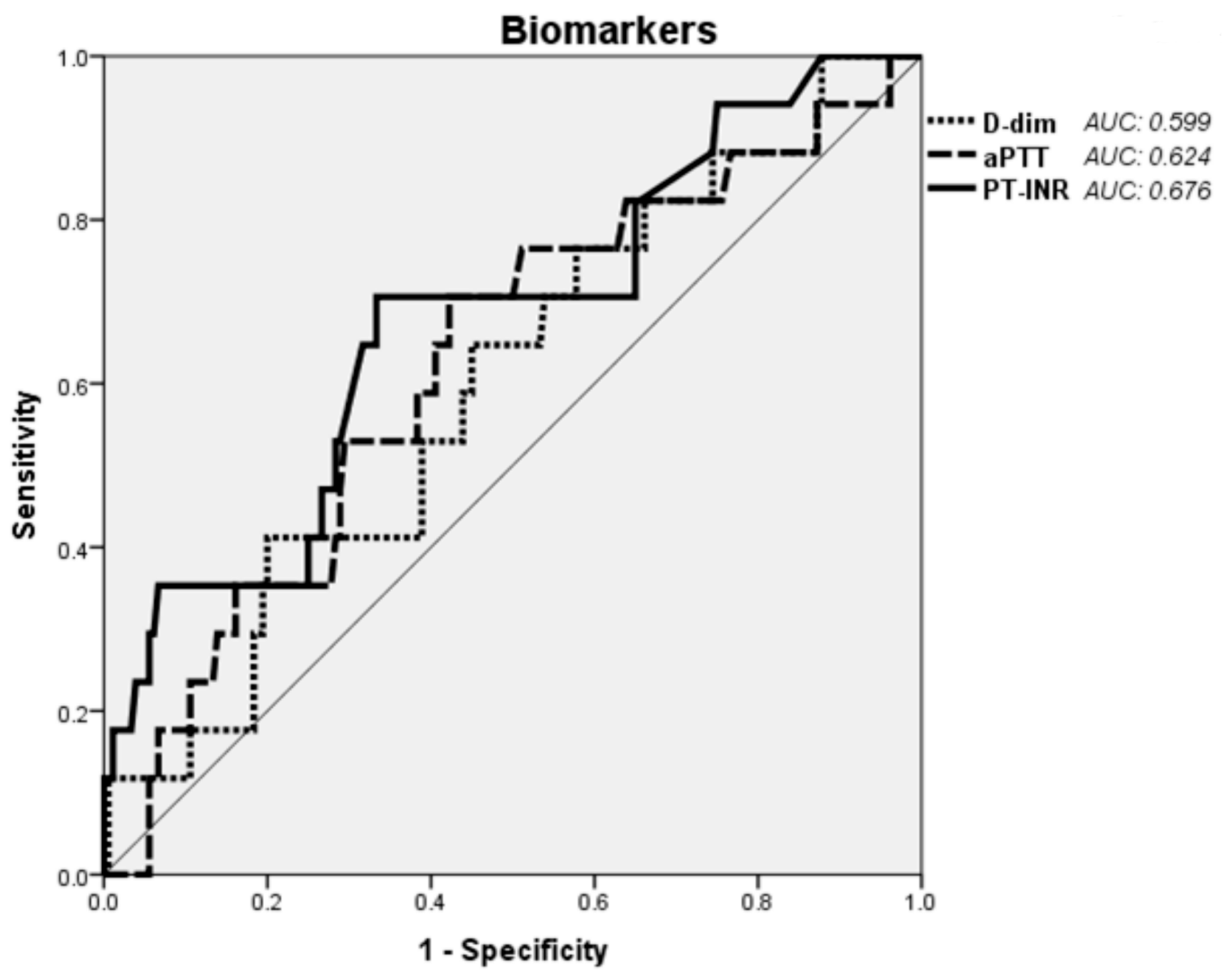

Figure 1. Receiver operating characteristic curve analysis of the predictive performance of three hemostasis parameters on in-hospital mortality of IE. Abbreviations: D-dim: D-dimers; aPTT: activated partial thromboplastin time; PT-INR: prothrombin time international normalized ratio.

The area under the receiver operating characteristic curve for each parameter is shown on the graph. Predictive power for the designated outcome was low for all three hemostasis parameters assessed.

\subsection{Hemostasis Parameters and IE Clinical Features}

Coagulation parameters were analyzed in relation to major IE clinical features (Table 2). Older age was associated with higher D-dimers levels $(p=0.047)$. Embolic events occurred in 104 patients $(30.9 \%)$ and were associated with higher levels of D-dimers $(p<0.001)$ and shorter aPTT $(p<0.001)$. Surgery was indicated in 246 of 337 patients $(73 \%)$, was actually performed in 208 of them (84\%) and showed an association with higher PT-INR levels $(p=0.013$; Table 2).

Regarding the type of infection (native vs. prosthetic valve vs. CIED), PT-INR was predictably higher in patients with PVE $(p<0.001)$. However, aPTT was also significantly more prolonged in the latter patient subgroup $(p=0.008)$. The PLT count was lower in rightsided IE, whilst CIED-related IE patients had the highest homocysteine levels. Median vegetation size in this patient subset was $15 \mathrm{~mm}$, and D-dimers were significantly higher in patients showing a vegetation size between 10 and $20 \mathrm{~mm}(p=0.041$; Supplementary Table S1).

Concerning IE etiology, S. aureus was associated with higher D-dimers $(p<0.001)$ and shorter aPTT levels ( $p=0.006$; Figure 2$)$. No other associations were observed in relation to the etiology of IE.

Median values of the analyzed parameters in each study subgroup are shown within the relevant bars. Significant associations were observed for higher D-dimers levels and shorter aPTT in S. aureus IE and a higher homocysteine level in IE due to coagulasenegative staphylococci. 

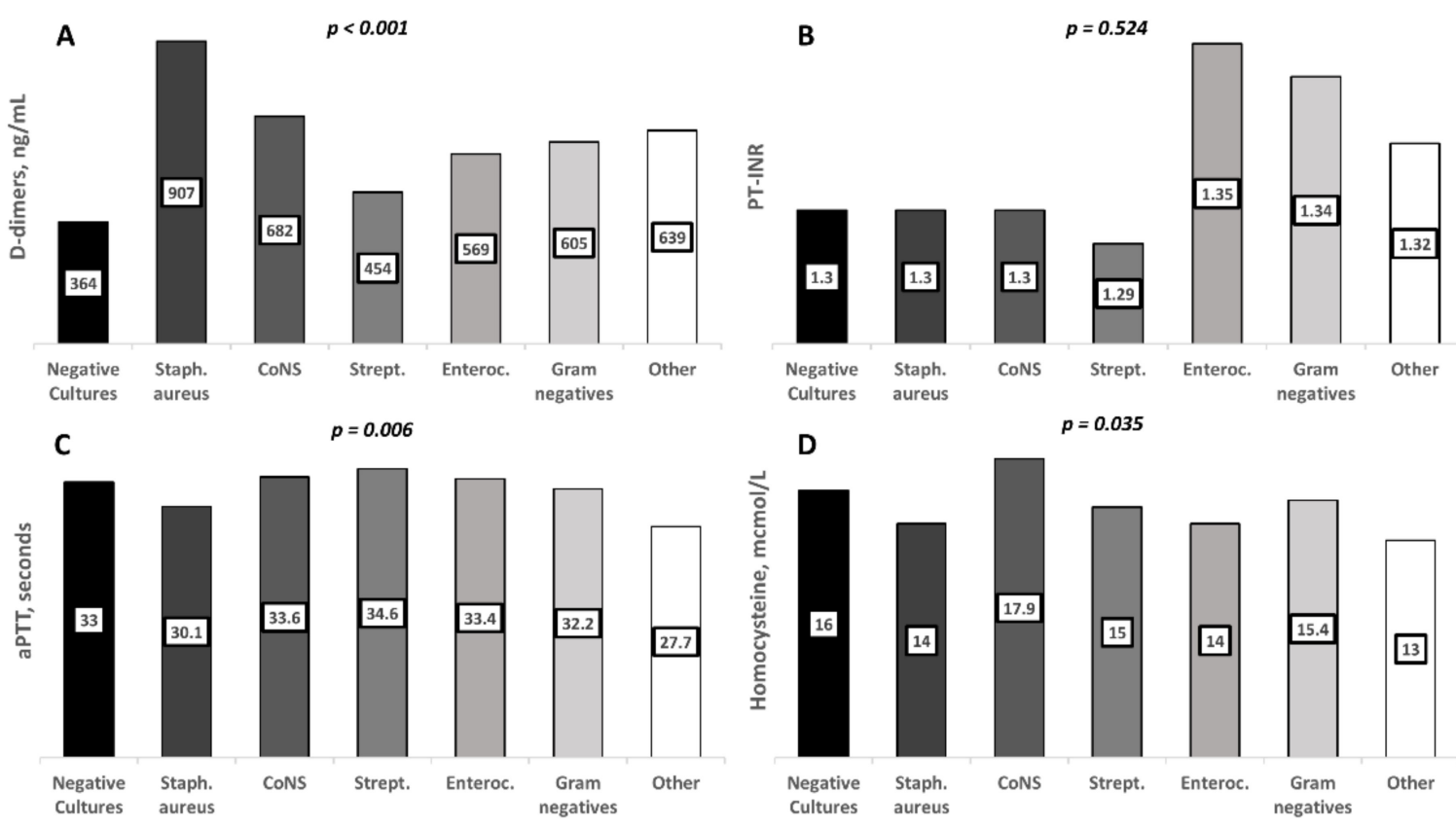

Figure 2. Hemostasis parameters according to the major subgroups of IE causative pathogens. Columns indicate median values for each subgroup: (A) D-dimers; (B) PT-INR; (C) aPTT; (D) homocysteine. Abbreviations: CoNS: coagulase-negative staphylococci; Strept: streptococci; Enteroc: Enterococci; PT-INR: prothrombin time international normalized ratio; aPTT: activated partial thromboplastin time.

\subsection{Hemostasis Parameters and Comorbidities}

The most common comorbidities in the 337 IE patients studied were chronic heart failure and diabetes mellitus, followed by chronic liver disease and chronic kidney disease (Table 1).

Two hundred and fifteen (63.8\%) patients presented at least one comorbidity. The median CCI was 5 (range 3-7). Table 4 shows coagulation parameters in relation to CCI. D-dimers and fibrinogen levels did not change according to CCI. In contrast, a J-shaped relationship was observed between $\mathrm{CCI}$ and the remaining hemostasis parameters. Patients with CCI $\leq 1$ or $\geq 4$ had a prolonged PT-INR $(p=0.006)$, and a trend for a longer aPTT $(p=0.057)$, a lower PLT count $(p=0.089)$ and a higher homocysteine level $(p=0.060)$ (Table 4).

Table 4. Coagulation parameters according to the Charlson Comorbidity Index in IE patients.

\begin{tabular}{|c|c|c|c|c|}
\hline CI & $0-1(n=22)$ & $2-3(n=34)$ & $\geq 4(n=142)$ & $p$-Value ${ }^{\wedge}$ \\
\hline D-dimers, ng/mL & $452(215-866)$ & 649 (337-1037) & $614(259-1222)$ & 0.439 \\
\hline Fibrinogen, $\mathrm{mg} / \mathrm{dL}$ & $439(383-605)$ & $423(355-580)$ & 409 (306-537) & 0.323 \\
\hline PT-INR & $1.35(1.25-1.58)$ & $1.20(1.09-1.37)$ & $1.33(1.20-2.14)$ & 0.006 \\
\hline aPTT, seconds & $33.2(29.3-38.2)$ & $30.9(29-34)$ & $33(30.1-38.4)$ & 0.057 \\
\hline Platelet count, cells $10^{3} / \mu \mathrm{L}$ & 209 (149-302.7) & $229(183-280)$ & $201(139-259)$ & 0.089 \\
\hline Homocysteine, mcmol/L & $14(11-16.2)$ & $12(11-18)$ & $15(12-21)$ & 0.060 \\
\hline
\end{tabular}

Data are median (IQR). ' Kruskal-Wallis test. Abbreviations: aPTT: activated partial thromboplastin time; PT-INR: prothrombin time international normalized ratio; CCI: Charlson Comorbidity Index; IE: infective endocarditis. Statistically significant results are marked in bold.

\section{Discussion}

Coagulation and inflammation are closely linked, and a prothrombotic tendency is often observed in acute infectious diseases $[9,22]$. In the present study, we evaluated the association of hemostasis parameters with the severity and prognosis of IE. Being inex- 
pensive routine tests, easy to obtain in every hospital, coagulation parameter assessments could improve the clinical management of IE.

Derived from one of the largest single-center cohorts of IE where hemostasis has been studied, our data suggest that coagulation parameters are strictly tied to the course and outcome of the disease. D-dimers were independently associated with in-hospital mortality, whereas aPTT was a predictor of 1-year mortality. In addition, higher levels of D-dimers and shorter aPTT, both signaling a pro-coagulant state, translated into a higher risk of embolic events. In contrast, the significance of PLT and fibrinogen levels remains unclear from our data.

Among coagulation parameters, D-dimers have received the most interest, and their use in clinical practice is well established. Our results corroborate previous data suggesting a predictive value of D-dimers for the short-term prognosis of IE and the prediction of embolism $[16,17,23,24]$ and septic embolic stroke [18]. Consistently, Meini et al. recently found that very high levels of D-dimers signaled a worse in-hospital outcome in patients with acute, severe infections [13].

Interestingly, aPTT levels also showed predictive value for IE outcomes. Their association with 1-year mortality needs to be elaborated as, to the best of our knowledge, no prior similar data exist. Apparently, a shorter aPTT implies a prothrombotic state that associates with IE embolic complications and staphylococcal etiology. Whether this relates to factor VIII or vVF levels remains to be studied. In contrast, longer aPTT may be associated with other forms of coagulopathy that signal a reduced chance of survival. PT-INR and aPTT are modified by anticoagulant treatment in patients with prosthetic valves or atrial fibrillation, and it is well known that PVE and arrhythmias imply a worse IE outcome and a higher incidence of embolism [25-27]. Overall, it is interesting to note that common coagulation parameters may provide more clinically relevant information in IE than other parameters that are more complex to obtain, such as homocysteine [28] and prothrombotic genetic polymorphisms [29].

Etiology also appeared to have an impact on coagulation function in IE. S. aureus was significantly associated with higher D-dimers levels and shorter aPTT, confirming and further supporting previous data about the role of $S$. aureus in the coagulation imbalance in IE $[10,11]$. Further investigation of the role of staphylothrombin inhibition by direct anticoagulants in S. aureus IE [12] seems warranted.

Comorbidities were common in our cohort, and a CCI $\geq 4$ was associated with specific changes in hemostasis parameters. Since previous studies highlighted the negative effect of comorbidities on IE outcome [30-32], we hypothesize that changes in coagulation function could represent one possible link between these two factors.

Our study has some limitations. First, it was a retrospective study. Second, some patients were referred to our unit from other facilities and were often treated before the diagnosis of IE, possibly altering the kinetics of coagulation parameters measured at hospital admission. Third, patients who underwent emergency surgery on hospital admission were excluded, thus leaving the more severe ones out of this study. Fourth, there was a sizeable amount of missing data, and a considerable number of patients were lost to the 1-year follow-up.

In conclusion, elevated D-dimers are associated with a higher risk for in-hospital mortality in IE patients. High D-dimers and a short aPTT are associated with a higher risk for embolic events in IE. A longer aPTT is associated with 1-year mortality. Hemostasis parameters appear to be inexpensive tools that are easy to obtain, which are able to improve the evaluation of IE prognosis.

Supplementary Materials: The following are available online at https://www.mdpi.com/article/ 10.3390/jcm10225386/s1, Supplementary Table S1: Coagulation parameters according to, site of infection, type of infection and vegetation size in IE patients. 
Author Contributions: R.Z. worked on concept of the study, drafted the manuscript and critically revised the manuscript; D.I. worked on the concept of the study, data collection and data interpretation drafted the manuscript and critically revised the manuscript; M.P.U. worked on data collection and data interpretation and critically revised the manuscript; L.B. worked on data collection and data interpretation and critically revised the manuscript; A.K. worked on data collection and data interpretation and critically revised the manuscript; R.M. critically revised the manuscript; G.E. worked on data collection and data interpretation and critically revised the manuscript; M.V. critically revised the manuscript; F.D. critically revised the manuscript; R.A. critically revised the manuscript; E.D.-M. worked on the concept of the study, drafted the manuscript and critically revised the manuscript. All authors have read and agreed to the published version of the manuscript.

Funding: This work was supported by an Italian Ministry of Research basic grant to R.Z. and by University of Campania research funds to E.D.-M.

Institutional Review Board Statement: This study was conducted according to the guidelines of the Declaration of Helsinki and was approved by the Ethics Committee of the University of Campania "Luigi Vanvitelli" and AORN OspedalideiColli (prot. N. AOC/011110/2020).

Informed Consent Statement: Informed consent was obtained from all the subjects involved in the study.

Data Availability Statement: The dataset used for this study is available on request to the corresponding author.

Conflicts of Interest: The authors have no conflict of interest to disclose relevant to the content of this study. E.D.-M. received grant support and personal fees, outside of this work, from Roche, Pfizer, MSD, Angelini, Advanz Pharma, Bio-Merieux, Abbvie, Nordic Pharma, Sanofi-Aventis, Medtronic and DiaSorin. R.Z. received personal fees, outside of this work, from Nordic Pharma.

\section{Appendix A}

Members of the Monaldi Hospital Cardiovascular Infection Study Group:

Emanuele Durante-Mangoni MD, PhD; Domenico Iossa PhD; Lorenzo Bertolino MD; Maria Paola Ursi MD; Fabiana D’Amico BSc; Arta Karruli MD; Mohammad Ramadan MD; Roberto Andini MD; Rosa Zampino MD (Internal Medicine); Mariano Bernardo MSc; Giuseppe Ruocco MSc (Microbiology); Giovanni Dialetto MD; Franco Enrico Covino MD; Sabrina Manduca MD (Echocardiography); Alessandro Della Corte MD, PhD; Luca S. De Santo MD, PhD; Antonio Carozza MD, PhD; Marisa De Feo MD, PhD (Cardiac Surgery); Stefano De Vivo MD (Electrophysiology); Maria Luisa De Rimini MD (Nuclear Medicine); Nicola Galdieri MD (Intensive Care Unit).

\section{References}

1. Murdoch, D.R.; Corey, G.R.; Hoen, B.; Miró, J.M.; Fowler, V.G.; Bayer, A.S.; Karchmer, A.W.; Olaison, L.; Pappas, P.A.; Moreillon, P.; et al. Clinical presentation, etiology, and outcome of infective endocarditis in the 21st century: The International Collaboration on Endocarditis-Prospective Cohort Study. Arch. Intern. Med. 2009, 169, 463-473. [CrossRef] [PubMed]

2. Habib, G.; Erba, P.A.; Iung, B.; Donal, E.; Cosyns, B.; Laroche, C.; Popescu, B.A.; Prendergast, B.; Tornos, P.; Sadeghpour, A.; et al. Clinical presentation, aetiology and outcome of infective endocarditis. Results of the ESC-EORP EURO-ENDO (European infective endocarditis) registry: A prospective cohort study. Eur. Heart J. 2019, 40, 3222-3232. [CrossRef]

3. Keynan, Y.; Rubinstein, E. Pathophysiology of Infective Endocarditis. Curr. Infect. Dis. Rep. 2013, 15, 342-346. [CrossRef]

4. Schwarz, C.; Hoerr, V.; Töre, Y.; Hösker, V.; Hansen, U.; Van De Vyver, H.; Niemann, S.; Kuhlmann, M.T.; Jeibmann, A.; Wildgruber, M.; et al. Isolating Crucial Steps in Induction of Infective Endocarditis with Preclinical Modeling of Host Pathogen Interaction. Front. Microbiol. 2020, 11, 1325. [CrossRef] [PubMed]

5. Hoerr, V.; Franz, M.; Pletz, M.; Diab, M.; Niemann, S.; Faber, C.; Doenst, T.; Schulze, P.; Deinhardt-Emmer, S.; Löffler, B. S. aureus endocarditis: Clinical aspects and experimental approaches. Int. J. Med. Microbiol. 2018, 308, 640-652. [CrossRef] [PubMed]

6. Werdan, K.; Dietz, S.; Löffler, B.; Niemann, S.; Bushnaq, H.; Silber, R.-E.; Peters, G.; Müller-Werdan, U. Mechanisms of infective endocarditis: Pathogen-host interaction and risk states. Nat. Rev. Cardiol. 2013, 11, 35-50. [CrossRef]

7. Liesenborghs, L.; Meyers, S.; Vanassche, T.; Verhamme, P. Coagulation: At the heart of infective endocarditis. J. Thromb. Haemost. 2020, 18, 995-1008. [CrossRef]

8. Vanassche, T.; Peetermans, W.E.; Herregods, M.-C.; Herijgers, P.; Verhamme, P. Anti-thrombotic therapy in infective endocarditis. Expert Rev. Cardiovasc. Ther. 2011, 9, 1203-1219. [CrossRef]

9. Verhamme, P.; Hoylaerts, M.F. Hemostasis and inflammation: Two of a kind? Thromb. J. 2009, 7, 15. [CrossRef] [PubMed] 
10. Liesenborghs, L.; Verhamme, P.; Vanassche, T. Staphylococcus aureus, master manipulator of the human hemostatic system. J. Thromb. Haemost. 2018, 16, 441-454. [CrossRef]

11. Vanassche, T.; Kauskot, A.; Verhaegen, J.; Peetermans, W.E.; van Ryn, J.; Schneewind, O.; Hoylaerts, M.F.; Verhamme, P. Fibrin formation by staphylothrombin facilitates Staphylococcus aureus-induced platelet aggregation. Thromb. Haemost. 2012, 107, 1107-1121. [CrossRef]

12. Peetermans, M.; Liesenborghs, L.; Peerlinck, K.; Van Wijngaerden, E.; Gheysens, O.; Goffin, K.E.; Hoylaerts, M.F.; Jacquemin, M.; Verhaegen, J.; Peetermans, W.E.; et al. Targeting Coagulase Activity in Staphylococcus aureus Bacteraemia: A Randomized Controlled Single-Centre Trial of Staphylothrombin Inhibition. Thromb. Haemost. 2018, 118, 818-829. [CrossRef]

13. Meini, S.; Sozio, E.; Bertolino, G.; Sbrana, F.; Ripoli, A.; Pallotto, C.; Viaggi, B.; Andreini, R.; Attanasio, V.; Rescigno, C.; et al. D-Dimer as Biomarker for Early Prediction of Clinical Outcomes in Patients with Severe Invasive Infections Due to Streptococcus Pneumoniae and Neisseria Meningitidis. Front. Med. 2021, 8, 627830. [CrossRef]

14. Scharrer, I. Procoagulant activity during viral infections. Front. Biosci. 2018, 23, 1060-1081. [CrossRef] [PubMed]

15. Sharma, S.K.; Rohatgi, A.; Bajaj, M.; Sprung, C.L.; Morales, R.C.; Kasdan, H.; Reiter, A.; Volker, T.; Meissonnier, J.; Beloborodova, N.; et al. Sepsis 2016 Agra, India. Crit. Care 2016, 20, 45. [CrossRef] [PubMed]

16. Turak, O.; Canpolat, U.; Özcan, F.; Yayla, Ç.; Mendi, M.A.; Öksüz, F.; Tok, D.; Tok, D.; Çağlı, K.; Gölbaşı, Z. D-dimer level predicts in-hospital mortality in patients with infective endocarditis: A prospective single-centre study. Thromb. Res. 2014, 134, 587-592. [CrossRef]

17. Lin, Y.-W.; Jiang, M.; Wei, X.-B.; Huang, J.-L.; Su, Z.; Wang, Y.; Chen, J.-Y.; Yu, D.-Q. Prognostic value of D-dimer for adverse outcomes in patients with infective endocarditis: An observational study. BMC Cardiovasc. Disord. 2021, 21, 1-7. [CrossRef]

18. Xu, N.; Fu, Y.; Wang, S.; Li, S.; Cai, D. High level of D-dimer predicts ischemic stroke in patients with infective endocarditis. J. Clin. Lab. Anal. 2020, 34, e23206. [CrossRef]

19. Habib, G.; Lancellotti, P.; Antunes, M.J.; Bongiorni, M.G.; Casalta, J.-P.; Del Zotti, F.; Dulgheru, R.; El Khoury, G.; Erba, P.A.; Iung, B.; et al. 2015 ESC Guidelines for the management of infective endocarditis: The Task Force for the Management of Infective Endocarditis of the European Society of Cardiology (ESC). Endorsed by: European Associ-ation for Cardio-Thoracic Surgery (EACTS), the European Association of Nuclear Medicine (EANM). Eur. Hear. J. 2015, 36, 3075-3128. [CrossRef]

20. Li, J.S.; Sexton, D.J.; Mick, N.; Nettles, R.; Fowler, J.V.G.; Ryan, T.; Bashore, T.; Corey, G.R. Proposed Modifications to the Duke Criteria for the Diagnosis of Infective Endocarditis. Clin. Infect. Dis. 2000, 30, 633-638. [CrossRef] [PubMed]

21. Mangoni, E.D.; Adinolfi, L.E.; Tripodi, M.F.; Andreana, A.; Gambardella, M.; Ragone, E.; Precone, D.F.; Utili, R.; Ruggiero, G. Risk factors for "major" embolic events in hospitalized patients with in-fective endocarditis. Am. Heart J. 2003, 146, 311-316. [CrossRef]

22. Durante-Mangoni, E.; Molaro, R.; Iossa, D. The role of haemostasis in infective endocarditis. Curr. Infect. Dis. Rep. 2014, 16, 435. [CrossRef]

23. Bakal, R.B.; Karakoyun, S.; Kahveci, G.; Ozveren, O.; Omaygenç, O.; Akpınar, S.H.; Akgün, T.; Ozdemir, N. Relationship between D-dimer and systemic embolism in patients with infective endocarditis. Turk Kardiyol Dern Ars 2013, 41, 589-594. [CrossRef]

24. Barış, V. Özgür D-Dimer is a Strong Predictor of in-hospital mortality in patients with Infective Endocarditis. Anatol. J. Cardiol. 2018, 21, 124-133. [CrossRef]

25. DiNubile, M.J.; Calderwood, S.B.; Steinhaus, D.M.; Karchmer, A.W. Cardiac conduction abnormalities complicating native valve active infective endocarditis. Am. J. Cardiol. 1986, 58, 1213-1217. [CrossRef]

26. Vongpatanasin, W.; Hillis, L.D.; Lange, R.A. Prosthetic heart valves. N. Engl. J. Med. 1996, 335, 407-416. [CrossRef] [PubMed]

27. Habib, G.; Thuny, F.; Avierinos, J.-F. Prosthetic Valve Endocarditis: Current Approach and Therapeutic Options. Prog. Cardiovasc. Dis. 2008, 50, 274-281. [CrossRef] [PubMed]

28. Iossa, D.; Molaro, R.; Andini, R.; Parrella, A.; Ursi, M.P.; Mattucci, I.; De Vincentiis, L.; Dialetto, G.; Utili, R.; Durante-Mangoni, E. Clinical significance of hyperhomocysteinemia in Infective Endocarditis: A case-control study. Medicine 2016, 95 , e4972. [CrossRef]

29. Durante-Mangoni, E.; Iossa, D.; Molaro, R.; Andini, R.; Mattucci, I.; Malgeri, U.; Albisinni, R.; Utili, R. Prevalence and significance of two major inherited thrombophilias in infective endocarditis. Intern. Emerg. Med. 2015, 10, 587-594. [CrossRef]

30. Hansen, L.; Ozga, A.-K.; Klusmeier, M.; Hillebrand, M.; Tulun, A.; Pannek, N.; Rieß, F.-C. The Freestyle Valve in Severe Necrotizing Aortic Root Endocarditis: Comorbidity Upon Outcome. Thorac. Cardiovasc. Surg. 2021. [CrossRef]

31. Nagai, T.; Takase, Y.; Hamabe, A.; Tabata, H. Observational Study of Infective Endocarditis at a Community-based Hospital: Dominance of Elderly Patients with Comorbidity. Intern. Med. 2018, 57, 301-310. [CrossRef] [PubMed]

32. Durante-Mangoni, E.; Bradley, S.; Selton-Suty, C.; Tripodi, M.F.; Barsic, B.; Bouza, E.; Cabell, C.H.; de Oliveira Ramos, A.I.; Fowler, V.; Hoen, B.; et al. Current features of infective endocarditis in elderly patients: Results of the International Collaboration on Endocarditis Prospective Cohort Study. Arch. Intern. Med. 2008, 168, 2095-2103. [CrossRef] [PubMed] 